\title{
DE QUE FALAM OS MARXISTAS QUANDO FALAM EM CLASSES?
}

\author{
Luis Felipe Miguel
}

\author{
Professor do Depto. de Ciência Política da Universidade de Brasília; \\ Doutor em Ciências Sociais pela Universidade Estadual de Campinas.
}

\begin{abstract}
$\mathrm{O}$ artigo discute o conceito de classes sociais segundo quatro autores marxistas - Nicos Poulantzas, E. P. Thompson, Adam Przeworski e Erik Olin Wright. São abordadas, em especial, as polêmicas referentes à determinação estrutural das classes e à localização dos setores intermediários da sociedade.
\end{abstract}

Palavras-chave: classes sociais; marxismo.

utilização da categoria "classe social" como
instrumento privilegiado de análise é vista,
em geral, como o traço distintivo da abordagem marxista nas ciências sociais. Ao mesmo tempo, talvez nenhum outro conceito divida tanto os autores que se dizem vinculados ao marxismo. Nenhum texto "canônico" pode ser invocado: o capítulo dedicado às classes é o mais frustrante de $O$ capital, interrompendo-se bruscamente após cinco curtos parágrafos introdutórios. (MARX, 1989, p.1123-1124) Em nenhum outro local Marx dá uma definição exaustiva de seu conceito de classes sociais.

Este artigo discute cinco tentativas de definição de classes sociais, de um ponto de vista marxista, feita por quatro autores diferentes: Nicos Poulantzas, E. P. Thompson, Adam Przeworski e Erik Olin Wright (que realizou duas sínteses teóricas relativas ao conceito de classes, ambas estudadas aqui). Evidentemente, estes autores não esgotam o debate sobre o tema - e outras posições serão citadas de passagem. Mas são todos nomes "de primeiro time", e formam um grupo bastante representativo. São autores de diferentes nacionalidades, vinculados a tradições distintas dentro do marxismo.

Poulantzas, meio grego e meio francês, produziu sob influência decisiva do estruturalismo de Althusser. Thompson, expoente da fértil historiografia marxista inglesa, assumiu o papel de inimigo número um do althusserianismo. Przeworski, polonês que trabalha no ambiente acadêmico norte-americano, é um neomarxista que utiliza as teorias dos jogos e da escolha racional como instrumental analítico. ${ }^{1} \mathrm{O}$ quarto autor é o californiano Wright, que estudou com Christopher Hill, em seguida aproximou-se do estruturalismo francês e ultimamente aderiu ao marxismo analítico - sem, entretanto, ser um rational choicist ortodoxo.

Mas, apesar da inserção no marxismo acadêmico - inclusive de Thompson, o mais militante e menos acadêmico dos quatro - os autores têm em comum a preocupação com a vinculação entre a teoria e a prática do movimento operário. Polemizar a respeito da natureza das classes sociais não é, para nenhum deles, envolver-se numa disputa a respeito de categorias abstratas. É sempre uma tentativa de entender melhor a sociedade capitalista mesmo que esse entendimento exija um recuo até um período pré-capitalista, como no caso de Thompson - e as maneiras de transformá-la.

\section{CLASSES E LUTAS}

O primeiro grande ponto de polêmica está ligado à possibilidade de determinação objetiva — ou não — das classes sociais. Para alguns autores, as classes são derivadas das estruturas sociais e, especificamente, das relações de propriedade. Das posições dentro das relações de propriedade são deduzidas as posições de classe. Para outros, pelo contrário, as classes são formadas no processo histórico de luta de classes. Neste caso, de nada vale o esquema abstrato da estrutura social, sem referência às práticas historicamente estabelecidas.

Com matizes, a primeira perspectiva é a de Wright e Poulantzas; a segunda, de Thompson e Przeworski. Mas estão excluídas, neste elenco de autores, as posições extremas e simplificadoras. O "objetivismo" de Wright e Poulantzas não

Rev. Mediações, Londrina, v. 3, n. 1, p. 23-29, jan./jun. 1998 
estabelece nenhum tipo de vinculação mecânica entre as relações de propriedade e as classes sociais, conforme rezam as cartilhas do marxismo vulgar. É Poulantzas quem afirma que

\begin{abstract}
"as classes sociais significam para o marxismo, em um e mesmo movimento, contradições e luta das classes: as classes sociais não existem a priori, como tais, para entrar em seguida na luta de classe, o que deixa supor que existiriam classes sem luta das classes. As classes sociais abrangem as práticas de classe, isto é, a luta das classes", (POULANTZAS, 1975, p.14)
\end{abstract}

raciocínio que parece fazer eco às lições de Thompson.

Por sua vez, Przeworski e Thompson também se distanciam da definição voluntarista de classes, que extrapola os limites do marxismo ao igualá-las a movimentos sociais ou grupos de pressão. Nenhum deles está disposto a negar a existência de determinantes objetivos para a formação das classes sociais. Thompson se manifesta contra a noção de que "a formação de classe é independente de determinações objetivas, que classe pode ser definida simplesmente como uma formação cultural etc." (THOMPSON, 1978, p.149) ${ }^{2}$

O campo comum que reúne esses quatro autores é balizado ainda por dois outros pontos. Nenhum deles aceita a distinção, marcadamente hegeliana, que Marx faz, em alguns textos, entre classe em si e classe para si-e que se tornou um dos pilares da versão vulgarizada do conceito de classe. E todos aceitam, em algum grau, a centralidade da luta de classes na sociedade capitalista, ao contrário de alguns pós-marxistas, como Ernesto Laclau, que vêem uma pluralidade de clivagens sociais deslocando o papel central da divisão de classes no capitalismo contemporâneo. (LACLAU 1986, p.42) $^{3}$

Dentro deste campo de consenso, no entanto, as diferenças são profundas. Poulantzas, a despeito da menção às práticas de classe citada acima, vai enfatizar a determinação estrutural das classes sociais. O que muda e o que vai ser talvez a lição mais importante de sua análise, influenciando marcantemente os estudos posteriores - é a idéia de que a determinação estrutural não se limita à determinação econômica:

\begin{abstract}
"uma classe social define-se pelo seu lugar no conjunto das práticas sociais, isto é, pelo seu lugar no conjunto da divisão social do trabalho, que compreende as relações políticas e as relações ideológicas. A classe social é, neste sentido, um conceito que designa o efeito de estrutura na divisão social do trabalho." (POULANTZAS, op. cit., p.14) ${ }^{4}$
\end{abstract}

Embora a primeira tentativa que Wright faz de construir o conceito de classes, no livro Classe, crise $e$ Estado, tenha a forma de uma polêmica com Poulantzas, os dois autores concordam quanto a este ponto. Wright também é cuidadoso e evita um objetivismo radical, que reduza classes e lutas de classes à condição de meros epifenômenos das relações de propriedade. Mas o esquema a que chega revela a primazia da estrutura (objetiva) de classe sobre a luta (prática) de classe.
Wright criou uma tipologia, com seis diferentes formas de "determinação estrutural". (WRIGHT, 1981, p.1623) Aplicando esses conceitos à relação entre estrutura de classe e luta de classe, ele chega à conclusão de que a primeira impõe limites à segunda, que, por sua vez, transforma a primeira. (idem, p.95-97) ${ }^{5}$ Assim, o papel da luta de classes se torna eminentemente reativo. Em sua segunda síntese teórica, o livro Classes, ele assume a posição objetivista de forma ainda mais clara. Wright afirma então que a existência estrutural das classes é irredutível a suas organizações coletivas, às ideologias de classes ou à luta de classes. (WRIGHT, 1985, p.28) ${ }^{6}$ Esse seria, segundo Wright, um pressuposto marxista básico.

Seguindo uma tendência comum a outros autores marxistas, ${ }^{7}$ Wright irá, em sua segunda teoria, fazer da exploração o elemento constitutivo básico do conceito de classe. $O$ conceito de exploração, por sua vez, será extraído da obra de outro marxista analítico, John Roemer, autor de A general theory of exploitation and class. Sem entrar nos detalhes da teoria de Roemer, basta fixar que, para ele, exploração é toda divisão desigual de benefícios materiais em que as vantagens dos beneficiários dependem da existência de prejudicados, ou seja, em que uma alteração para melhor na situação do prejudicado implicaria em piorar a situação do beneficiário. Remetendo à exploração, o conceito de classe ganha um fundamento objetivo, independente da consciência dos agentes.

Ao fazer da existência estrutural das classes um pressuposto básico do marxismo, Wright se dirige a um adversário em especial: E. P. Thompson. A perspectiva teórica do historiador Thompson fica evidente já a partir do título de sua obra mais importante, A formação da classe operária inglesa. O termo "formação" - e mais ainda no original inglês, "making of' — implica um processo que não é dado, que se faz. No prefácio ao livro, Thompson expõe sua visão do que é uma classe:

\begin{abstract}
"um fenômeno histórico, que unifica uma série de acontecimentos díspares e aparentemente desconectados, tanto na matéria prima da experiência como na consciência. Ressalto que é um fenômeno histórico. Não vejo a classe como uma 'estrutura', nem mesmo como uma 'categoria', mas como algo que ocorre efetivamente (e cuja ocorrência pode ser demonstrada) nas relações humanas." (THOMPSON, 1987, p.9)
\end{abstract}

Mais do que um conceito elaborado de classe, Thompson busca defender este entendimento da classe enquanto acontecimento histórico. Envolvido em polêmica sobre o tema, não se dispõe a refinar ou aprofundar essa abordagem - antes, aponta problemas em visões concorrentes. Dois elementos, entretanto, podem ser destacados:

1) uma perspectiva assumidamente subjetivista das classes sociais. Thompson admite a utilização da classe como categoria heurística ou analítica, mas insiste que este uso deve ser criteriosamente distinguido da classe enquanto "reference to real, empirically observable correspondent historical content'. (THOMPSON, 1978, p.148) Esta classe com conteúdo histórico correspondente, real e empiricamente observável, é a que surge na sociedade industrial capitalista 
do século XIX. A utilização heurística ou analítica do conceito carrega, portanto, um anacronismo - que Thompson irá remeter à consciência dos agentes. Se as pessoas não vivem suas experiências e seus conflitos enquanto classes, mas enquanto "ordens", "estados" ou "hierarquias", o conceito de classe deverá ser entendido como um instrumental que pode ser útil, mas sempre imperfeito e marcado por esse anacronismo;

2) a visão da luta de classes como um conceito prévio e muito mais universal em relação a classes. A partir da luta de classes, as pessoas se descobrem enquanto classes. (idem, p.49) ${ }^{8}$ Esse descobrimento, cabe frisar, não é a percepção de uma realidade já dada que ainda se mantivesse encoberta. Não é a produção de uma consciência que leva a classe em si a se tornar uma classe para si. É um fazer-se, como assinala o título do livro de Thompson, em que não há nenhuma classe em si objetiva como ponto de chegada predeterminado.

A primazia da luta de classe, e portanto das práticas, é o ponto da visão de Thompson mais contestado por seus críticos. G. A. Cohen exemplifica o tom dessas críticas. Ele observa, em primeiro lugar, que a dificuldade em determinar o local que uma pessoa ocupa nas relações de propriedade não invalida a utilização deste local como critério para a definição de sua posição de classe. E acrescenta:

"Sua consciência, cultura e política não entram na definição de sua posição de classe. De fato, estas exclusões são requeridas para proteger o caráter substantivo da tese marxiana de que a posição de classe condiciona fortemente a consciência, cultura e política." (COHEN, 1980, p.73) ${ }^{9}$

Przeworski irá apresentar uma posição próxima à de Thompson, embora mais matizada. No caso de Thompson, é a relevância dada ao processo histórico que o impelirá a negar a "classe estruturalmente determinada" abstrata. No caso de Przeworski, esta negação está ligada à sua adesão ao individualismo metodológico. Em lugar de um nicho numa estrutura, Przeworski sempre estará vendo a classe como algo que é, em última análise, redutível a "uma variedade de pessoas". (PRZEWORSKI, 1989, p.111) Isso não o impede, porém, de incluir aspectos de determinação material em sua definição das classes.

Assim, Przeworski retira de Poulantzas a idéia de que

\begin{abstract}
"as relações ideológicas e políticas são objetivas com respeito às lutas de classes. Assim, pelo menos dois tipos de determinação tornaram-se distintos: a determinação, pelas relações de produção, da organização de relações ideológicas e políticas e a determinação, pela totalidade dessas relações objetivas, das relações entre os homens e mulheres concretos que são seus portadores, inclusive as relações de lutas de classes." (idem, p.87)
\end{abstract}

E se manifesta contrário ao espontaneísmo embutido em certas afirmações de Thompson. No entanto, ele está próximo deste último no ponto essencial, que é o entendimento de que "as classes são formadas como efeito de lutas". (idem, p.91)

Ele tira daí uma imagem da formação das classes como processo perpétuo, uma vez que a dinâmica do conflito social está permanentemente desorganizando e reorganizando classes. Przeworski irá então se aproximar — mas apenas se aproximar - da perspectiva de Laclau, já citada, segundo a qual as classes deixam de ser a clivagem essencial para a prática política no capitalismo contemporâneo. Mas seus pressupostos são diferentes. Para Laclau, a ampliação do tempo livre e do poder aquisitivo da classe operária proporcionou uma multiplicação dos papéis sociais dos indivíduos. Não haveria porque continuar a privilegiar o papel determinado pela posição nas relações de produção em detrimento dos papéis determinados pelo gênero, etnia, consumo, etc. Laclau, portanto, vê uma alteração nas relações de produção que é estrutural, embora seja conseqüência de lutas de classe - a ampliação do tempo livre e da renda operária — , causando a diminuição da importância do pertencimento de classe para a ação política.

A visão de Przeworski é completamente diversa. Ele parte da estratégia dos partidos operários, que investiram na ampliação de sua base política e eleitoral, debilitando, assim, o vínculo classista que mantinham a princípio. Dessa forma, fragilizaram o papel da classe no seio das próprias lutas que formam a classe. Isso leva "ao ressurgimento de outras bases de identificação coletiva (...) O processo de organização das massas desorganiza os operários". (idem, p.98) A debilitação da clivagem de classes como linha de força básica da luta política é efeito, para Przeworski, de uma estratégia política, e não está necessariamente relacionada a nenhum tipo de transformação nas condições de trabalho.

O que Przeworski promove, portanto, é uma leitura das classes sociais nos termos dos problemas da ação coletiva. Trata-se de uma tendência importante nos estudos recentes sobre classes, que Jon Elster radicaliza ao ponto de dissolver as classes dentro da teoria da ação coletiva, negando-lhes qualquer centralidade. (ELSTER, 1985, p.390-391)

Os autores aqui analisados, em suma, estabelecem um continuum de posições teóricas. Começando por uma abordagem mais objetivista, com Wright II (a segunda síntese de Erik Olin Wright, Classes), passa-se a seguir por Wright I (Classe, crise e o Estado), Poulantzas e Przeworski, para se chegar, enfim, a Thompson, o mais subjetivista de todos. Entre os dois extremos, há pouca coisa em comum. Wright II verá como básico numa perspectiva marxista exatamente aquilo que Thompson rejeita: a irredutibilidade das classes, estruturalmente determinadas, às suas organizações e ideologia. E Thompson, que, salvo melhor juízo, nunca se referiu a Wright, certamente o veria como expoente de uma visão estática, que nega o que o marxismo oferece de melhor enquanto materialismo histórico.

\section{OS SETORES INTERMEDIÁRIOS}

O segundo ponto de polêmica se refere ao estatuto das chamadas "classes médias". Como é lugar-comum observar, na obra de Marx as classes surgem em dois registros diferentes. Nas análises abstratas, Marx aponta para uma polarização entre duas classes antagônicas em cada modo de produção ${ }^{10}$ (o locus classico desta visão é o Manifesto 
comunista); em análises concretas (como em $O$ dezoito brumário) surge uma quantidade muito maior de classes em luta, mas não há preocupação com uma conceituação rígida. Alimentou-se, nos primórdios do marxismo, a crença de que o hiato entre a abstração e a realidade iria diminuir ou mesmo desaparecer: que, com o avanço do capitalismo, as classes intermediárias entre burguesia e operariado seriam suprimidas. Ocorreu, antes, um movimento inverso, com a complexificação crescente da estrutura de classes e o inchamento dos estratos intermediários.

Torna-se necessário saber onde encaixar estes estratos médios: aproximando-os da pequena burguesia, do proletariado, da burguesia ou então construindo para eles um espaço à parte. Isso significa que eles criam a necessidade da formulação de critérios mais rigorosos para a definição de todas as classes sociais. Cada alternativa terá uma repercussão diferente na formulação de uma estratégia operária. Encarar um trabalhador de colarinho branco como operário (mesmo que ele ainda não saiba que é um operário ${ }^{11}$ implica em definições políticas diversas das que surgiriam de uma visão deste trabalhador como apenas um aliado potencial da classe operária, ou como um pequeno burguês que deverá manter uma posição oscilante entre as classes antagônicas fundamentais.

Naturalmente, a preocupação com a localização destes novos estratos se manifesta sobretudo entre os autores que vêem uma determinação estrutural nas posições de classe. Para aqueles que encaram as classes como o resultado de processos de lutas concretas, o problema não é tão importante. De fato, para Thompson, esta é uma questão que não se coloca. Se a classe é uma formação histórica, "definida pelos homens enquanto vivem sua própria história", (THOMPSON, 1987, p.12) não faz sentido determinar fronteiras a priori.

Przeworski, que ao contrário de Thompson, estuda o problema, irá concluir que são exatamente as práticas de classe que definirão as fronteiras de classe. Sua preocupação é a classe operária. Ele vai utilizar a imagem de círculos na superfície da água para descrever os diversos alcances possíveis do conceito de proletariado. Há um núcleo inconteste de trabalhadores manuais, empregados na indústria; em volta dele, vários grupos de pessoas que não possuem meios de produção, sejam empregados de escritório, trabalhadores intelectuais strictu sensu, executivos de empresas ou desempregados; finalmente, uma borda pequeno burguesa, que ainda detém meios de produção mas que está cada vez mais submetida ao controle do capital e que possui condições de vida próximas da proletária. (PRZEWORSKI, op. cit., p.75)

Para Przeworski, nenhum destes círculos estabelece precisamente $o$ limite da classe operária. Na verdade, eles abrem diferentes alternativas de ação política operária, e será essa ação política que irá delimitar as fronteiras do pertencimento de classe. (idem, p.112-113) Para Wright, ao contrário, a identificação incorreta dos limites de classe irá prejudicar o estabelecimento de uma estratégia operária. De seu ponto de vista, a determinação estrutural de classes impõe aos agentes interesses objetivos, pois ligados à exploração. (WRIGHT, 1985, p.36) A ação política deverá levar em conta esses interesses; portanto, o estabelecimento das fronteiras de classe é uma tarefa prévia à formulação da estratégia política socialista.

Também para Poulantzas a confusão entre a classe operária e outras camadas sociais terá efeitos nefastos para o movimento socialista:

\begin{abstract}
"A identidade suputada e o amálgama operado entre esses interesses [da "nova classe média"] e aqueles da classe operária se fazem, como por acaso, pervertendo, a longo prazo, os interesses próprios da classe operária, única classe revolucionária até o fim, de forma que se possam confundir com aqueles conjuntos." (POULANTZAS, 1975, p.221)
\end{abstract}

Poulantzas vai considerar insuficiente a dupla de critérios que correntemente é utilizada para definir as localizações de classe no modo de produção capitalista. Essa dupla inclui os critérios da propriedade dos meios de produção e do trabalho. Dela surgiriam duas classes fundamentais, o proletariado (não possui meios de produção/trabalha) e a burguesia (possui meios de produção/não trabalha), e uma intermediária, a pequena burguesia (possui meios de produção/trabalha). O problema é que essa definição de proletariado pode incluir tanto o alto executivo quanto o trabalhador braçal, empregados da indústria e de serviços, em suma, toda pessoa que viva de salário — o segundo círculo na água, segundo a metáfora de Przeworski.

Para lutar contra essa dificuldade, Poulantzas irá refinar tanto o critério de propriedade quanto o de trabalho. Irá distinguir, em primeiro lugar, propriedade econômica ("o poder de afetar os meios de produção para determinadas utilizações e dispor assim dos produtos obtidos") e posse ("o domínio do processo de trabalho"). (idem, p.19) ${ }^{12}$ Isso permitirá incluir todo o grupo dos administradores, que detêm posse mas não propriedade, dentro da burguesia.

Em segundo lugar, Poulantzas vai estabelecer distinções entre trabalho produtivo e trabalho improdutivo, trabalho manual e trabalho intelectual. Trabalho produtivo é aquele que gera mais-valia diretamente, contraposto ao trabalho que permanece na esfera da realização desta maisvalia ou da circulação do capital. Trabalho manual é aquele no qual o trabalhador estabelece contato direto com a matéria que irá transformar. Seriam proletários apenas os trabalhadores manuais produtivos. Todos os outros formariam uma camada que Poulantzas irá chamar de "nova pequena burguesia".

Torna-se necessário, então, justificar a inclusão, numa mesma classe social, de dois grupos tão distintos quanto a pequena burguesia tradicional (artesãos, pequenos comerciantes) e a nova pequena burguesia (trabalhadores de colarinho branco, técnicos, profissionais assalariados). Poulantzas vai argumentar que, apesar das determinações estruturais distintas, os dois grupos sofrem os mesmos efeitos ideológicos. (idem, p.313) Portanto, o critério básico para a definição das fronteiras de classe passa a ser esse. As determinações estruturais são importantes na medida em que proporcionam os efeitos ideológicos; e se efeitos ideológicos similares surgem de duas determinações estruturais 
completamente diversas, como é o caso, ambos os grupos devem ser enquadrados na mesma classe social.

$\mathrm{O}$ adversário que Poulantzas busca derrotar, antes de mais nada, é a idéia de que é possível existirem, na sociedade, posições exteriores às classes:

\begin{abstract}
"As classes sociais só seriam assim uma esquematização do real, seu 'esqueleto' de alguma forma extraído do real por uma simples operação de abstração, sendo os conjuntos exteriores às classes precisamente a riqueza de determinação do concreto que escapa à sua 'rede' de inteligibilidade." (idem, p.216)
\end{abstract}

Pois o esforço de Wright, em sua primeira síntese teórica, será produzir uma definição de classes que recuse, simultaneamente, a noção de tipo-ideal criticada por Poulantzas e a "anexação" forçada a classes produzida por Poulantzas.

Segundo Wright, Poulantzas adota uma definição muito rígida para a classe operária, que acaba por reduzi-la a uma parcela insignificante da população. Seria uma definição incorreta já a partir da distinção entre trabalho produtivo e improdutivo. Todos os trabalhadores explorados têm interesse "objetivo" no socialismo, independente se de sua mão-de-obra se extrai mais-valia ou apenas redução de custos. (WRIGHT, 1981, p.47) Não faria sentido, argumenta Wright, limitar a burguesia aos setores produtivos da economia. O mesmo vale para a classe operária.

Contra Poulantzas, Wright propõe um conceito de "localizações contraditórias" de classes. Nem todas as posições na estrutura social, ele diz, "podem ser vistas como solidamente ancoradas numa única classe; alguns posicionamentos ocupam objetivamente situações contraditórias entre as classes". (idem, p.30) Assim, gerentes e administradores ocupariam um lugar contraditório entre a burguesia e o proletariado.

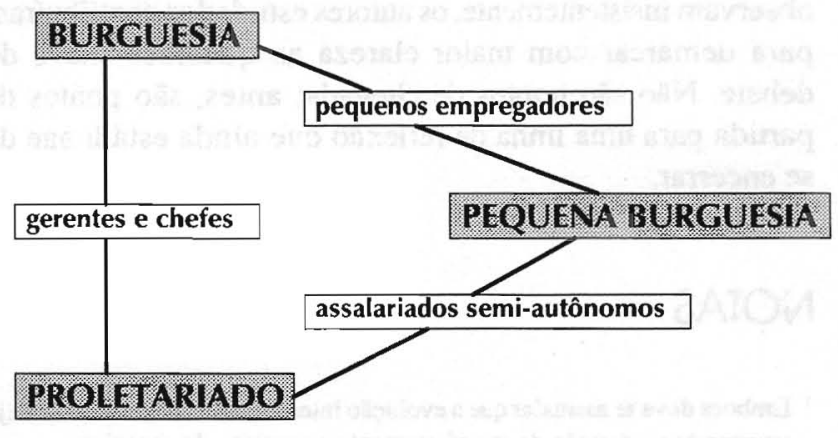

Fonte: WRIGHT (1981, p.59).

Executivos, gerentes e supervisores possuem situação contraditória entre a burguesia e o proletariado porque não possuem propriedade, mas em alguma medida exercem posse dos meios de produção. A distinção de Wright é semelhante à de Poulantzas. Propriedade é "controle sobre investimentos e meios físicos de produção"; posse é "controle sobre a operação, autoridade". Mais tarde, o quadro foi sofisticado, com a inclusão de "operadores de franquias" entre pequenos empregadores e gerentes, e de "tecnocratas sem cargos de gerência" (non-manangerial technocrats) entre gerentes e empregados semi-autônomos. (WRIGHT, 1985, p.47-48)

O descontentamento de Wright com esse primeiro modelo é devido ao deslocamento do conceito de exploração pelo de dominação, que "enfraquece a ligação entre a análise de localizações de classe e a análise de interesses objetivos", (idem, p.56) que, conforme visto antes, são objetivos exatamente na medida em que estão vinculados à exploração. Isso também tende a diluir a dominação de classe entre as "múltiplas opressões" sociais. (idem, p.57)

Wright julga que o conceito de exploração, que extrai de Roemer, permite encontrar a solução também para o problema das "localizações contraditórias". Segundo ele, cada modo de produção teria um diferente mecanismo de exploração predominante. Wright lista quatro modos de produção: feudalismo, capitalismo, "estatismo" (de tipo soviético) e um hipotético socialismo.

\begin{tabular}{l|c|c|c}
\hline $\begin{array}{c}\text { Estrutura } \\
\text { de classes }\end{array}$ & $\begin{array}{c}\text { Principal bem que } \\
\text { é desigualmente } \\
\text { distribuído }\end{array}$ & $\begin{array}{c}\text { Mecanismo } \\
\text { de exploração }\end{array}$ & Classes \\
\hline feudalismo & força de trabalho & $\begin{array}{c}\text { extração coerciva } \\
\text { de trabalho } \\
\text { excedente }\end{array}$ & $\begin{array}{c}\text { senhores e } \\
\text { servos }\end{array}$ \\
\hline capitalismo & meios de produção & $\begin{array}{c}\text { trocas mercantis } \\
\text { de força de trabalho } \\
\text { e mercadorias }\end{array}$ & $\begin{array}{c}\text { capitalistas e } \\
\text { operários }\end{array}$ \\
\hline estatismo & organização & $\begin{array}{c}\text { distribuição do } \\
\text { excedente baseada } \\
\text { na hierarquia }\end{array}$ & $\begin{array}{c}\text { administradores } \\
\text { e não- } \\
\text { administradores }\end{array}$ \\
\hline socialismo & habilidades (skills) & $\begin{array}{c}\text { redistribuiçãonego- } \\
\text { ciada do excedente } \\
\text { de trabalhadores } \\
\text { para experts }\end{array}$ & $\begin{array}{c}\text { experts e } \\
\text { trabalhadores }\end{array}$ \\
\hline
\end{tabular}

Fonte: WRIGHT (1985, p.83)

Para Wright — bem como para POULANTZAS (1975, p.216-217) - convivem, numa formação social concreta, elementos de diferentes modos de produção. Por isso, no capitalismo moderno também se sentem os efeitos de mecanismos de exploração de outras estruturas de classes. Assim, haveria dois tipos de classes médias. Uns não seriam nem explorados nem exploradores, isto é, possuiriam exatamente o nível per capita do bem relevante na estrutura de classes (pequena burguesia tradicional). Outros são explorados numa dimensão e exploradores em outras. É a nova pequena burguesia assalariada, explorada em relação à posse dos meios de produção mas exploradora em relação aos recursos organizacionais ou às habilidades técnicas. (WRIGHT, 1985, p.86-87)

A partir daí, Wright produz uma grade com doze localizações de classe possíveis. Burgueses, pequenos empregadores (que empregam mas também trabalham) e pequenos burgueses são proprietários de meios de produção; os assalariados completam as nove posições restantes segundo a quantidade (menor, igual ou superior à média) de "ativos organizacionais" e "ativos de qualificação" que possuam. (idem, p.88) (13 $^{3}$ Julga, enfim, ter alcançado um critério objetivo e material, que chama de "conceito de classe centrado na exploração" (exploitation centred concept of class), capaz de enquadrar os diversos tipos de novos 
assalariados e de estabelecer a distância de cada um em relação ao proletariado. ${ }^{14}$

As críticas a esse conceito são variadas, começando pelo conceito de exploração de Roemer,

\begin{abstract}
"uma forma de abstração completamente imprópria imprópria no sentido que elimina aspectos não meramente contingentes, mas absolutamente fundamentais, da exploração como ela realmente ocorre na sociedade capitalista (...) Seu método de conceitualização da exploração é inteiramente arbitrário, na medida em que é possível situar a existência de formas diversas de exploração na base de experimentos mentais que são limitados apenas pela imaginação do teórico." (BURRIS, 1988, p.64)
\end{abstract}

Para outro autor, Meiksins, Wright não é capaz de justificar porque distinções de qualificação ou de hierarquia devem ser vistas como "mais do que formas de diferenciação e desunidade dentro das classes polares da sociedade capitalista". (MEIKSINS, 1988, p.77) Sobretudo, nada indicaria que "exploradores" no âmbito da organização ou da qualificação desenvolvessem interesses de classe específicos. Johanna Brenner, então, irá observar que a teoria de Wright é incapaz de explicar a conexão entre os interesses objetivos, determinados pela exploração, e a consciência (de classe) dos atores sociais. (BRENNER, 1988, p.88)

\section{CONCLUSÃO}

Está longe das pretensões e das possibilidades deste artigo oferecer uma "resposta" para os problemas envolvidos na conceitualização de classe ou indicar qual o "mais correto" entre os autores estudados. Em vez disso, indicarei alguns pontos que julgo importantes no debate.

Em primeiro lugar, todos os autores mostram a tendência de reduzir o alcance da teoria de classes, tal como estabelecida pelo marxismo ortodoxo. Aqueles que vêem as classes como o resultado de processos de lutas tendem a aceitar a relevância de outros atores sociais — embora não cheguem necessariamente, como Laclau ou mesmo Elster, à dissolução das classes em meio aos diversos grupos de ação coletiva. Os outros, que procuram manter a determinação estrutural para as divisões de classe, estão constantemente tentados a estabelecer novos critérios para sua definição, uma vez que as relações de propriedade mostram-se cada vez mais complexas. Em suma, ou se reduz a centralidade das classes no conflito social, ou se reduz a centralidade das relações de propriedade nas classes.

A principal "tentação" é a inclusão do critério da autoridade como definidor das fronteiras de classe. Ralf Dahrendorf, um autor não-marxista que realizou um compreensivo estudo do conceito de classe a partir da obra de Marx, chega à conclusão de que a autoridade é $o$ critério por excelência - e que a propriedade é uma forma especial de autoridade. (DAHRENDORF, 1982, p.127-131) Poucos marxistas assinariam embaixo. Mas a noção de autoridade está presente em todas as distinções entre propriedade e posse, feitas por autores como Poulantzas ou Wright I.
Mesmo Wright II, com todos os seus protestos de fidelidade à teoria da exploração de Roemer, não escapa dessa apreciação. Como anota Val Burris, a propriedade dos ativos de organização, característica da exploração no modo de produção estatista, é "indistinguível do exercício da autoridade hierárquica". (BURRIS, op. cit., p.62)

A inclusão do exercício da autoridade como critério é fruto da influência de Max Weber sobre parte do pensamento marxista. Há, de outro lado, influências ainda mais marcantes do individualismo metodológico (inclusive em Thompson) ${ }^{15}$ e da filosofia analítica. É um marxismo, portanto, que se abre para o diálogo com outras tendências da ciência social. Um marxismo que ganha em refinamento teórico e em capacidade de apreensão da complexidade dos fenômenos sociais - e que, por isso, se vê diante de problemas que não admitem respostas fáceis. Um marxismo, enfim, que caminha para sua própria dissolução enquanto corpo doutrinário fechado, integrando-se de pleno direito numa ciência social não-dogmática, que seguramente tem Marx como uma de suas referências essenciais, mas apenas uma, entre outras.

A questão do conceito de classe social é um exemplo: um desafio aos cientistas sociais, cuja resposta não prescinde da contribuição de Marx, mas não se esgota nela. Embutida na questão está toda a problemática da relação entre agência e determinação estrutural. Wright, que ao responder a seus críticos se mostra um polemista notavelmente aberto a novas perspectivas, observa que um conceito de classe centrado na formação de identidades é um valioso enfoque alternativo ao seu. E conclui, corretamente, que a manutenção destes enfoques diversos é mais útil do que qualquer tentativa de forçá-los numa síntese mecânica, destinada "a retardar, mais do que enriquecer, o desenvolvimento da teoria das classes". (WRIGHT, 1988, p.106)

Em suma, sem que tenham conseguido apresentar soluções inteiramente satisfatórias, como seus polemistas observam insistentemente, os autores estudados contribuíram para demarcar com maior clareza as questões-chave do debate. Não são pontos de chegada; antes, são pontos de partida para uma linha de reflexão que ainda está longe de se encerrar.

\section{NOTAS}

\footnotetext{
1 Embora deva se assinalar que a evolução intelectual de Przeworski esteja ocorrendo na direção de um afastamento completo do marxismo.

2 Todas as citações em língua estrangeira foram traduzidas pelo autor.

${ }^{3}$ Também incorporam, em diferentes medidas, a crença marxista no papel potencialmente transformador da classe operária, ao contrário, por exemplo, das provocantes análises de André Gorz. Ver, de Gorz, Adeus ao proletariado e, sobretudo, a excelente análise do capitalismo avançado em Métamorphoses du travail.

4 Ver também POULANTZAS (1986, p.61).

5 Ver, especialmente, o quadro à p. 96.

6 Uma aplicação mais extensa do quadro teórico estabelecido em Classes é feita por Wright em seu livro seguinte, Class counts: comparative studies in class analyses.
} 
${ }^{7}$ Ver, por exemplo, Ste. Croix: "classe (...) é a expressão social coletiva do fato da exploração, a maneira pela qual a exploração é incorporada numa estrutura social". (STE. CROIX, 1984, p.100)

${ }^{8}$ Ver, sobre este aspecto do pensamento de Thompson, ANDERSON (1980, p.41-42)

9 A polêmica contra Thompson ocupa as p.73-77 do livro.

${ }^{10}$ Apesar do trecho de Teorias da mais-valia, em que critica Ricardo por não perceber "o crescimento constante das classes de permeio, situadas entre trabalhadores, de um lado, e capitalistas e proprietários das terras, do outro". MARX (1983, p.1007)

${ }^{11}$ Essa é, por exemplo, a posição de Lojkine, teórico do PCF. Ver LOJKMNE (1990, p.29-63).

${ }^{12}$ Na primeira citação, "afetar" é visivelmente uma tradução incorreta do verbo francês "affecter", que significa também "destinar".

${ }^{13}$ Ver também WRIGHT (1997, p.25).

${ }^{14}$ No entanto, ao tentar "provar" seu conceito, Wright é inconsistente com seus próprios pressupostos. Num extenso survey realizado na Suécia e nos Estados Unidos, ele procurou mostrar que as posições políticas e o nível de renda dos entrevistados se aproximavam ou se afastavam daqueles da classe operária conforme sua posição na "grade" das localizações de classe se aproximava ou se afastava do nicho do proletariado. Mas, a rigor, renda e opinião política não deveriam ser critérios decisivos numa conceituação estrutural de classes. Wright acaba voltando à predominância do nível ideológico, que critica na junção, feita por Poulantzas, entre a nova pequena burguesia e a pequena burguesia tradicional. O survey e a análise de seus resultados ocupam a segunda metade de Classes; junto com outros surveys internacionais, compõem a maior parte do material estudado em Class counts. Para uma crítica da pesquisa de Wright, ver MEIKSINS (1988, p.81).

${ }^{15}$ Basta ver certas passagens de A miséria da teoria (THOMPSON, 1981); p. ex., p.111.

\section{REFERÊNCIAS BIBLIOGRÁFICAS}

ANDERSON, Perry. Arguments within english marxism. London: New Left Books, 1980.

BRENNER, Johanna. Work relations and the formations of class consciousness. In: Critical Sociology, v. 15, n. 1, Eugene (Oregon), 1988.

BURRIS, Val. New directions in class analysis. In: Critical Sociology, v. 15, n. 1, Eugene (Oregon), 1988.

COHEN, G. A. Karl Marx's theory of History: a defence. Princeton: Princeton University Press, 1980.

DAHRENDORF, Ralf. As classes e seus conflitos na sociedade industrial. Brasília: Editora da UnB, 1982.

ELSTER, Jon. Making sense of Marx. Cambridge/Paris: Cambridge University Press/Éditions de la Maison des Sciences de l'Homme, 1985.

GORZ, André. Adeus ao proletariado. Rio de Janeiro: Forensel Universitária, 1987

Métamorphoses du travail: quête du sens. Critique de la raison économique. Paris: Galilée, 1988.

LACLAU, Ernesto. Os novos movimentos sociais e a pluralidade do social. In: Revista Brasileira de Ciências Sociais, v. 1, n. 2, São Paulo, 1986.

LOJKINE, Jean. A classe operária em mutações. Belo Horizonte: Oficina de Livros, 1990.

MARX, Karl. Teorias da mais valia. v. 2. São Paulo: Difel, 1983.

El capital. 6.ed. v. 8, t. III. México: Siglo XXI, 1989.

MEIKSINS, Peter F. A critique of Wright's theory of contradictory class locations. In: Critical Sociology, v. 15, n. 1, Eugene (Oregon), 1988.

POULANTZAS, Nicos. As classes sociais no capitalismo de hoje. Rio de Janeiro: Zahar, 1975.
Fontes, 1986.

PRZEWORSKI, Adam. Capitalismo e social-democracia. São Paulo: Companhia das Letras, 1989.

STE. CROLX, Geoffrey de. Class in Marx's conception of History, ancient and modern. In: New Left Review, n. 146, London, 1984.

THOMPSON, E. P. Eighteenth-century english society: class struggle without class? In: Social History, v. 3, n. 2, Millwood (New York), 1978.

A miséria da teoria. Rio de Janeiro: Zahar, 1981.

A formação da classe operária inglesa. 2.ed. v. 1. Rio de Janeiro: Paz e Terra, 1987.

WRIGHT, Erik Olin. Classe, crise e o Estado. Rio de Janeiro: Zahar, 1981. Classes. London: Verso, 1985.

Exploitation, identity, and class structure: a reply to my critics. In: Critical Sociology, v. 15, n. 1, Eugene (Oregon), 1988.

Class counts: comparative studies in class analysis. Cambridge: Cambridge University Press, 1997. 